\title{
Rigid block and finite element analysis of settlement-induced failure mechanisms in historic masonry walls
}

\author{
Raffaele Landolfo, Raffaele Gagliardo, Lucrezia Cascini, Francesco Portioli \\ Department of Structures for Engineering and Architecture, University of Naples "Federico II", Italy \\ landolfo@unina.it, bttp:// orcid.org/0000-0002-8695-669X \\ raffaele.gagliardo@unina.it, bttp:/ / orcid.org/0000-0003-0625-0417 \\ lucrezia.cascini@unina.it,http://orcid.org/0000-0003-3872-7371 \\ fportiol@unina.it, bttp://orcid.org/0000-0003-2711-3366
}

\author{
Marialaura Malena, Giovanni Tomaselli, Gianmarco de Felice \\ Department of Engineering, University of Roma Tre, Italy \\ marialaura.malena@uniroma3.it, bttp://orcid.org/0000-0002-0011-672X \\ giovanni.tomaselli@uniroma3.it, bttp://orcid.org/0000-0002-0917-0220 \\ gianmarco.defelice@uniroma3.it http://orcid.org/0000-0003-4921-2955
}

\begin{abstract}
The paper is related to the assessment of failure mechanisms of historic masonry structures suffering settlements induced by ground movements. Two numerical strategies are adopted in order to study the influence of the masonry shape and the settled zone on the cracking of masonry buildings: a discrete rigid block model and a continuous homogenized model. The first approach provides an estimate of the failure pattern of masonry based on the lower bound theorem of limit analysis. The second approach is formulated in the framework of multi-surface plasticity and is implemented in a finite element code for path-following non-linear analysis of masonry walls, described as continuous anisotropic plates. Several configurations of masonry walls under vertical settlement are investigated and the corresponding failure patterns resulting in local or global failure modes are presented. The results of the two models are compared and discussed in order to highlight pros and cons of discrete and continuous formulations in the prediction of settlement-induced damage of masonry structures.
\end{abstract}

KEYWORDs. Masonry; Settlement; Rigid Blocks; Limit Analysis; Finite Element Analysis.

\section{OPEN ACCESS}

Citation: Landolfo, R., Gagliardo, R., Cascini, L., Portioli, F., Malena, M., Tomaselli, G., de Felice, G., Rigid block and finite element analysis of settlement-induced failure mechanisms in historic masonry walls, Frattura ed Integrità Strutturale, 51 (2020) 517-533.

Received: 29.07.2019

Accepted: 12.12.2019

Published: 01.01.2020

Copyright: (C) 2020 This is an open access article under the terms of the CC-BY 4.0, which permits unrestricted use, distribution, and reproduction in any medium, provided the original author and source are credited.

\section{INTRODUCTION}

istoric masonry structures have frequently suffered damages from ground movements and soil settlement. These phenomena have increased due to tunneling and underground parking excavation in urban area. Therefore, there is a need for developing assessment tools for the prediction of damage that should be based on a proper 
description of the masonry structure and its non-linear behaviour. A number of approaches for the prediction of settlementinduced damages were proposed in the literature that consider masonry either as an assembly of discrete blocks [1-9] or as a continuum medium [10-19]. The comparison between discrete and continuous models to study masonry behaviour is also a widespread topic [20-22].

Aiming at comparing the outcomes of the two modelling strategies, in this study, a discrete Rigid Block Limit Analysis (RBLA) and a continuous Finite Element Analysis (FEA) are used. The adopted RBLA model considers the structure as a collection of rigid blocks interacting through no tension contact surfaces, under the assumption of infinite compressive strength. This model is part of the concave contact formulation, where the interaction takes place in the contact points located at the block vertexes. Due to the assumption of infinite compressive strength, the failure condition is reached through joint opening and sliding among the blocks at the contact interfaces. The adopted non-linear three-dimensional FEA model represents the masonry wall as an elasto-perfectly plastic homogenized Love-Kirchhoff plate [23, 24]. The model, formulated in the framework of multi-surface plasticity, is implemented in a FE code for the path-following analysis, by means of a minimization algorithm directly derived from the Haar-Karman principle. The output of such a formulation is represented by capacity curves derived from specific load and constrain conditions. In a previous paper [23] the authors carried out a comparison for masonry walls subjected to lateral forces, with the purpose of simulating the seismic behavior. In the present paper, the comparison is extended to the case of settlements, using appropriate loading and boundary conditions. More precisely, a masonry façade arranged in a running bond pattern and subjected to uniform settlement is investigated. Since the aim of the study is more on the prediction of the behaviour of masonry up to failure, the simplest simulation of the ground settlement is considered, in which part of the support moves downwards up to the attainment of failure in the structure. This simulation was originally proposed in [25] and supported by simple experiments to provide an overview of the damage pattern in existing masonry buildings. Clearly, the failure pattern strongly depends on the position and size of the moving support.

The influence of the following parameters is investigated: block size and shape, joint frictional properties, width of the settled area. The influence of the openings and of additional live loads on the structural behavior under settlement is also examined.

The results from the two numerical models are compared in terms of failure pattern induced by the settlement and corresponding reduction of the ground support reaction that is requested to activate the motion.

The paper is organized as follows: the rigid block model and the formulation governing the settlement-induced collapse prediction are presented in the following section. Then the formulation of the homogenized anisotropic constitutive model adopted for FEA is briefly outlined. Finally, a case-study is presented, consisting in the façade of an historic masonry building and the results obtained from RBLA and FEA are illustrated and compared.

\section{MODELLING OF SETTLEMENT}

7 he ground movement induced settlement is numerically simulated, according to [25], by applying a vertical downward displacement to the ground support and detecting the displacement of the structure, considering a cohesionless frictional interface at the base. The imposed displacement induces a progressive reduction of the vertical reaction at the base of the masonry structure, up to a limit value corresponding to the self-weight of the portion of the wall involved in the settlement, according to the attained failure configuration.

The RBLA returns the expected failure pattern together with the value of the base reaction in terms of load factor (or collapse multiplier), expressing the reaction which activates the failure mechanism. The path-following FEA provides the capacity curve in term of vertical base reaction $f_{s}$ versus the displacement imposed to the movable block and the strain pattern at each step of the analysis up to failure.

\section{THE RIGID BLOCK MODEL FOR LIMIT ANALYSIS}

he first formulation adopted deals with a rigid block model for limit analysis of historic masonry structures modelled as assemblages of polyhedral elements. The formulation assumes a frictional behaviour along blocks interfaces and considers no-tension and infinite compressive strengths at contact interfaces. The model is formulated for 3D assemblages and is herein used to investigate the in-plane behaviour of wall panels.

The interaction between blocks $i$ and $i+1$ is simulated by means of a concave contact formulation, where the internal forces are associated to the contact points $k$ located at the corners of the interfaces $j$ (Fig. 1). The internal forces are collected in a 
vector $\boldsymbol{c}$ with normal forces $n_{k}$ and shear forces $t_{1 k}$ and $t_{2 k}$. The limit analysis problem for settlement-induced collapse is formulated in terms of a cone programming problem, in the context of the lower bound limit analysis theorem, as follows [3]:

$$
\begin{array}{ll}
\max & \alpha \\
\text { s.t. } & \boldsymbol{A c}=\boldsymbol{f}_{\boldsymbol{D}}+\alpha \boldsymbol{f}_{\boldsymbol{S}} \\
& \boldsymbol{c} \in\left\{c_{k} \in \mathbb{R}^{3}: \mu n_{k} \geq \sqrt{t_{1 k}^{2}+t_{2 k}^{2}}, n_{k} \geq 0\right\}
\end{array}
$$

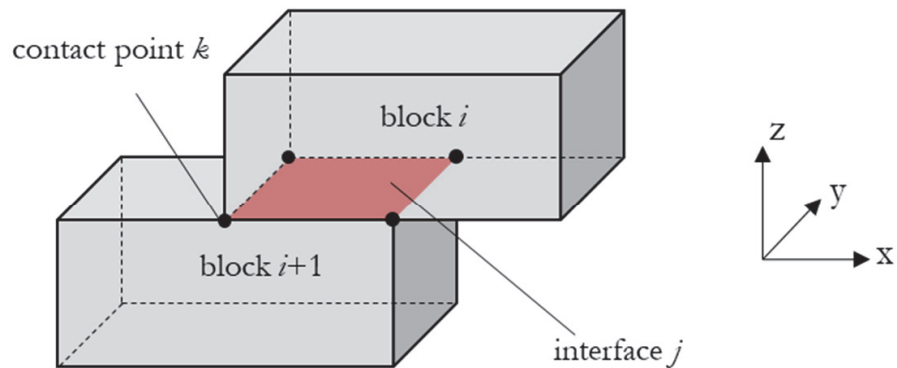

a)

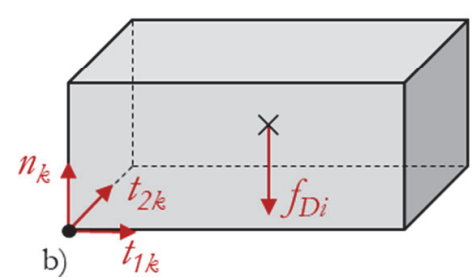

Figure 1: Blocks $i$, contact interfaces $j$ and contact points $k$ adopted in the rigid block model for limit analysis (a); internal contact forces at contact points and dead loads at blocks centroid (b).

The unknowns of the optimization problem are the load factor $\alpha$ and the vector of internal forces $c$. In the problem (1), the first constraint represents the equilibrium condition between internal static variables associated to contact interactions and external loads, being $\boldsymbol{A}$ the equilibrium matrix of the rigid block model. $\boldsymbol{f}_{\boldsymbol{D}}$ and $\boldsymbol{f}_{\boldsymbol{S}}$ are, respectively, the vector of dead loads and the vector of the support reaction at the moving support which is used to model the settlement.

The second constraint in problem (1) represents the Coulomb failure condition and corresponds to a convex cone which is a function of variables $t_{1 k}, t_{2 k}, n_{k}$ and of the friction coefficient $\mu$. The failure mode and the relevant kinematic variables corresponding to the upper bound (dual) formulation of the limit analysis problem are derived from the Lagrange multipliers associated to the solution of the static problem (1).

The vector of dead loads collects the gravity loads $\boldsymbol{f}_{\boldsymbol{D} \boldsymbol{i}}$ associated to the unit weight $\rho$ and volume $V_{i}$ of the block $i$ in the wall panel (or to the permanent loads associated to floor loads). An initial value $f_{D s}$ of the dead load is also assigned to the additional rigid block which is used to model the moving support, and which is associated to the single degree of freedom governing the ground movement, i.e. the vertical displacement. As such, the vector $\boldsymbol{f}_{\boldsymbol{D}}$ can be expressed follows:

$$
\boldsymbol{f}_{\boldsymbol{D} \boldsymbol{i}}=\left[\begin{array}{llllll}
0 & 0 & -\rho V_{i} & 0 & 0 & 0
\end{array}\right]^{\mathrm{T}} ; \boldsymbol{f}_{\boldsymbol{D}}=\left[\begin{array}{lllll}
\boldsymbol{f}_{\boldsymbol{D} 1} & \cdots & \boldsymbol{f}_{\boldsymbol{D} \boldsymbol{i}} & \cdots & f_{D s}
\end{array}\right]^{\mathrm{T}}
$$

The value $f_{D s}$ is intended to be representative of the reaction at the base support in the initial configuration (i.e. the configuration before settlement) and is assigned as a factor of the total weight of the model. Differently from lateral loads analysis, in the case of settlement analysis, a varying load $\alpha \boldsymbol{f}_{\boldsymbol{S}}$ is applied to the centroid of the moving support block only. This load is directed downwards and is expressed as a factor of the initial value $f_{D s}$.

As such, the vector $\boldsymbol{f}_{\boldsymbol{S}}$ can be expressed as follows.

$$
\boldsymbol{f}_{\boldsymbol{S}}=\left[\begin{array}{lllll}
0 & \ldots & 0 & \ldots & -f_{D s}
\end{array}\right]^{\mathrm{T}}
$$

and the magnitude of the reaction at the moving support corresponding to the onset of the failure mechanism is $(1-\alpha) f_{D s}$ 
The formulation is able to consider both associative and non-associative flow rules for the frictional behaviour at contact interfaces. When an associative behaviour is considered, the sliding at contact points involves both normal and tangential displacement rates. In such a case, the value of the load factor represents an upper bound on the non-associative collapse multiplier.

A simple iterative solution procedure was implemented to consider non-associative behaviour as well, where the failure at contact interfaces does not involve dilatancy. The iterative procedure solves the cone programming problem described in (1) by means of fictious failure conditions which involve zero dilatancy behaviour. For more details, the reader is referred to [3].

\section{THE HOMOGENIZED CONTINUUM MODEL FOR FINITE ELEMENT ANALYSIS}

he second constitutive model is an elasto-perfectly plastic homogenized plate model for the path-following finite element non-linear analysis of masonry panels subject to both in-plane and out-of-plane loads [24, 26, 27]. According to the above referenced works, the elastic domain for the panel is assumed to coincide with the macroscopic strength condition defined in [27], derived by a homogenization procedure applied to a thin and periodic heterogeneous plate, made of 3D infinitely resistant blocks connected by Mohr-Coulomb interfaces obeying an associated flow rule. Since the domain so defined is no-smooth multi-surface domain, the model is formulated in the framework of infinitesimal multi-surface rate-independent plasticity. In the following, the only definition of the elastic domain is reported in the way to express the parameters on which it depends. For further details, the readers can refer to [24, 27].

The macroscopic elastic domain assumes the following form:

$$
E_{t}=\left\{\mathrm{t}:=(\mathbf{N}, \mathbf{M}) \mid f^{i}(\mathbf{N}, \mathbf{M}):=\mathbf{N}: \mathbf{E}+\mathbf{M}: \chi-c^{i} \leq 0 \quad \forall i \in[1, . ., m]\right\}
$$

where $\mathbf{N}, \mathbf{M}$ and $\mathbf{E}, \boldsymbol{\chi}$ are the vectors collecting the in-plane and the out-of-plane stresses and the strains, while $f(\mathbf{t})$ are the following $m=8$ independent planes, intersecting in a non-smooth way:

$$
\begin{aligned}
& f^{1-2}:=\mu_{b} N_{11}+\operatorname{tg}(\phi) N_{22} \pm\left(1+\operatorname{tg}(\phi) \mu_{b}\right) N_{12} \leq 0 \\
& f^{3-4}:=N_{22} \pm \frac{1}{\operatorname{tg}(\phi)} N_{12} \leq 0 \\
& f^{5-6}:=N_{22} \pm \frac{2}{h} M_{22} \leq 0 \\
& f^{7-8}:=(p+q) N_{22} \pm \frac{2}{h} M_{11}-\frac{2}{h}(q-p) M_{22} \leq 0
\end{aligned}
$$

with

$$
p=\frac{\operatorname{tg}(\phi)}{\mu_{b}} \frac{b}{4 b} \quad q=\frac{\operatorname{tg}(\phi)}{\mu_{b}} \sqrt{1+\left(\frac{b}{4 b}\right)^{2}}
$$

The elastic domain depends explicitly on the friction angle $\phi$ of the joints, on the aspect ratio $\mu_{b}=\frac{2 a}{b}$ of the blocks, being $a$ the height and $b$ the width of the blocks, and on the thickness $b$ of the plate. It is anisotropic as a consequence of the arrangement of the blocks within the assembly and it is unbounded in the direction of compression [24, 27]. In the present work, in-plane actions only are considered, while the effectiveness of the plate model under out-of-plane loads has been shown in other recent works [23, 24]. 


\section{THE CASE STUDY OF A MASONRY FAÇADE SUBJECTED TO SETTLEMENT}

I $\mathrm{n}$ this section, the numerical case study of a masonry façade subject to settlement is presented. The configuration and size of the façade are inspired to tuff masonry buildings in the area of Naples, Italy, dating back to XVIII century [28]. The façade consists of two stories with overall height of $12.0 \mathrm{~m}$, length of $20.0 \mathrm{~m}$ and thickness equal to $0.5 \mathrm{~m}$ (Fig. 2). A first analysis considers the façade without openings, while the subsequent analyses take into account the presence of two levels of openings with the goal of evaluating their effects on the settlement-induced failure mode. In the case of façade with openings, the lintels were modelled in order to reproduce the pattern and the effect of flat arches: blocks with an inclination angle of the head joints for RBLA, and material with corresponding bed joints orientation for FEA are adopted, as indicated in Figs. 2(b) and 2(d).
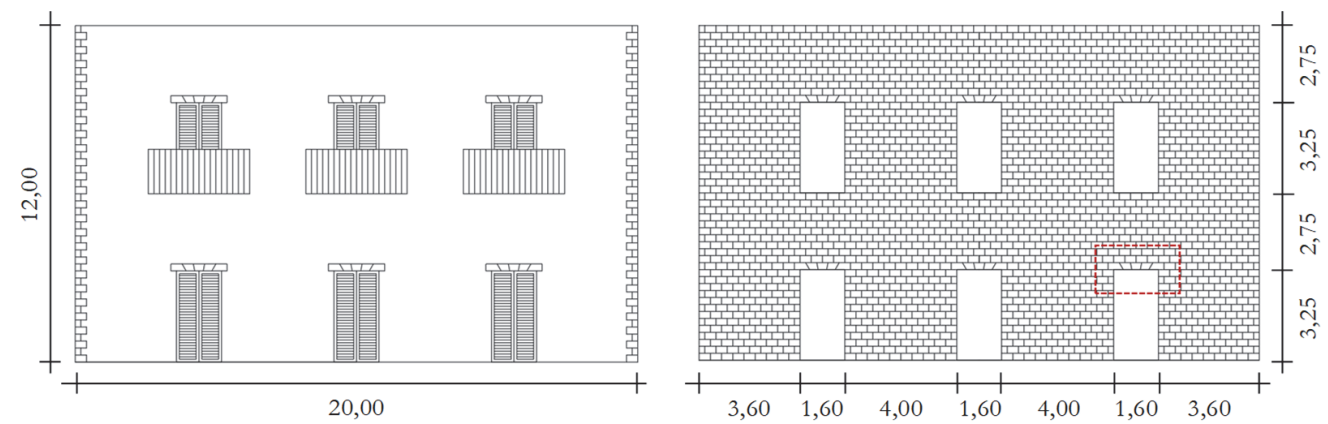

a)

b)
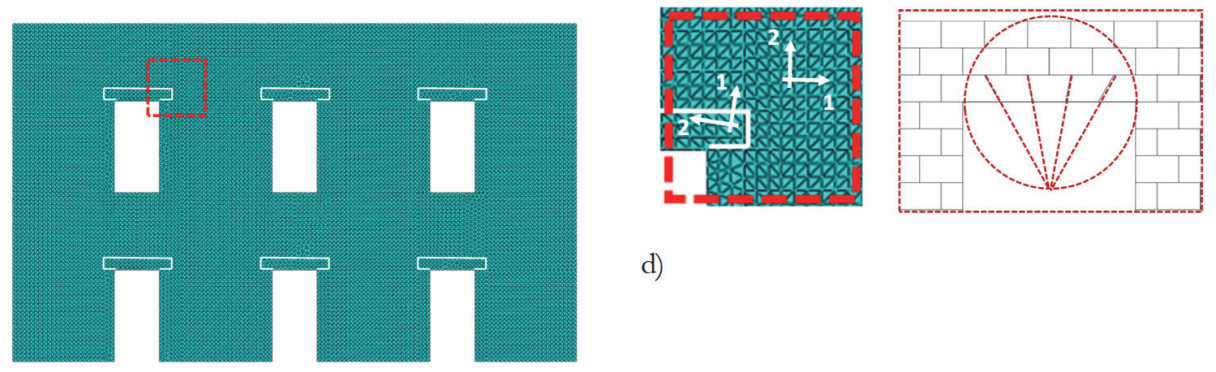

d)

c)

Figure 2: The case study of a masonry façade subject to settlement: the front side of the building (a), Rigid Block Model (b), Finite Element Model (c), and modeling details for the lintel (d).

It should be noted that the inclination of the joints in the lintels might affect the response of the investigated wall panels, especially if sliding failure is also taken into account, as it was in the present case. However, the analysis of the influence of the inclination angle and of the friction coefficient was out of the scope of the present study.

A parametric analysis is carried out to investigate the response when changing the width of ground settlement (Fig. 3), the block size and shape, the load provided by the slabs over the wall, and the presence of openings, as mentioned above.

Based on the parameters selected, either a local or a global failure mode is activated: the local failure is characterized by a uniform vertical displacement of the wedge located over the movable support, which detaches form the wall and fail according to a rigid body translation; the global failure mode is characterized by a more complex failure pattern, involving a greater portion of the wall and combining displacements and rotations of the block units.

According to [25], three movable ground support lengths are considered, namely short, medium and long settlement, corresponding respectively to $33 \%, 83 \%$ and $117 \%$ of the front height and to the $20 \%, 50 \%$ and $70 \%$ of the total length of the façade (Fig. 3).

Two masonry types are introduced aiming at studying to what extent the block shape could affect the failure pattern. The masonry tuff stones used in Naples during the modern and contemporary ages have been considered. The first tuff block shape, which is typical of the first decades of the XIX century, has height in the range $13-21 \mathrm{~cm}$ and height-to-length ratio equal to 1:2. The second tuff block shape, used in Naples at the end of the XVIII century, has height in the range 11-14 cm and length in the range $25-30 \mathrm{~cm}$. Accordingly, both the discrete and the continuous model have considered blocks with 25 
$\mathrm{cm}$ height and $40 \mathrm{~cm}$ length (1 $1^{\text {st }}$ typology) and $12 \mathrm{~cm}$ height and $25 \mathrm{~cm}$ length ( $2^{\text {nd }}$ typology). The mechanical properties have kept constant for both typologies: weight per unit volume equal to $16 \mathrm{kN} / \mathrm{m}^{3}$ and friction coefficient equal to 0.6 .

In the case of the RBLA model, two different assumptions were adopted at the contact interfaces: a non-associative behaviour with no friction on the vertical interfaces (type A), and an associative behaviour with finite friction on the vertical interfaces (type B). It should be noted that the results obtained from the FEA model are consistent with type B assumption, being related to an associative behaviour and to the use of the same value of the friction coefficient on vertical and horizontal contact interfaces.

a)

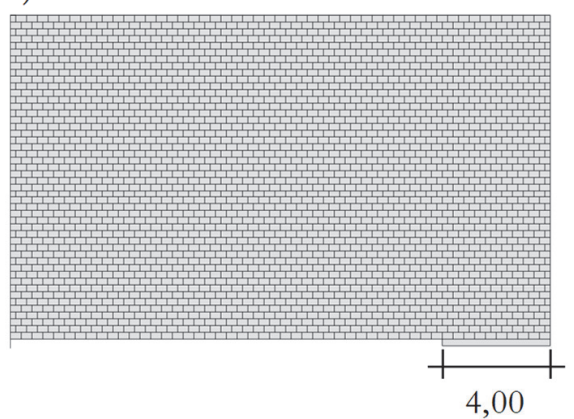

b)

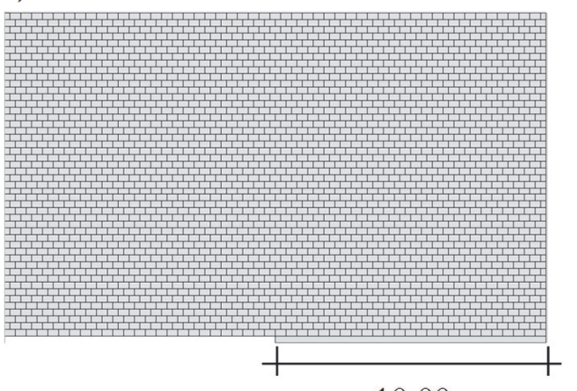

10,00 c)

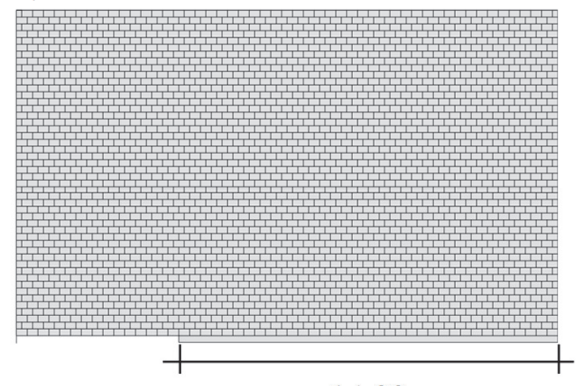

14,00

Figure 3: The settlement configurations on the base of movable support block length: short settlement (a), medium settlement (b) and long settlement (c).

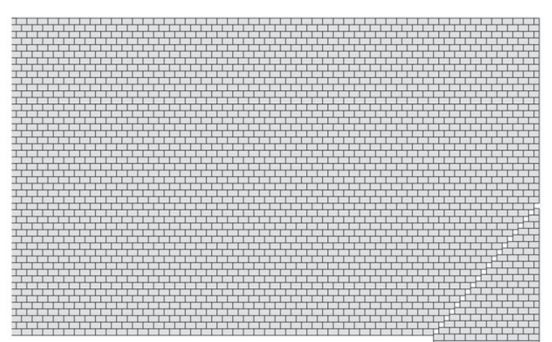

a)

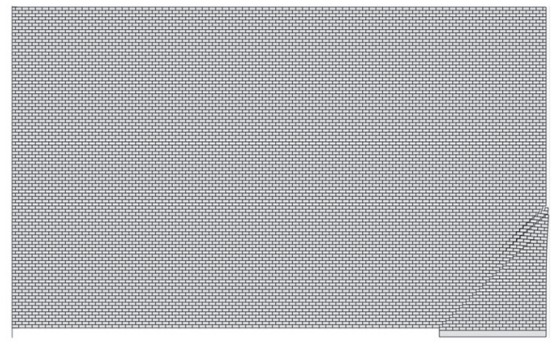

d)

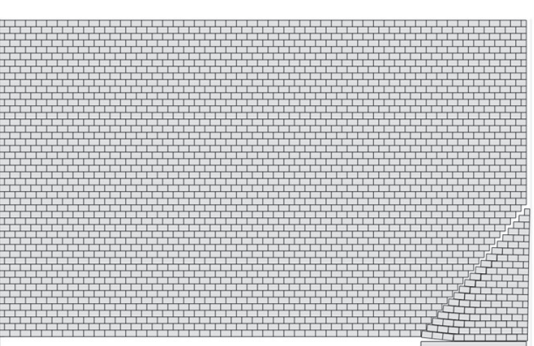

b)

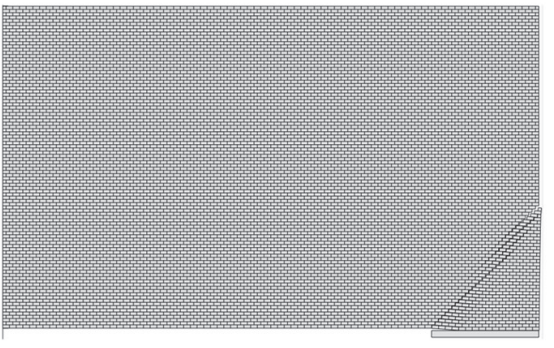

e)

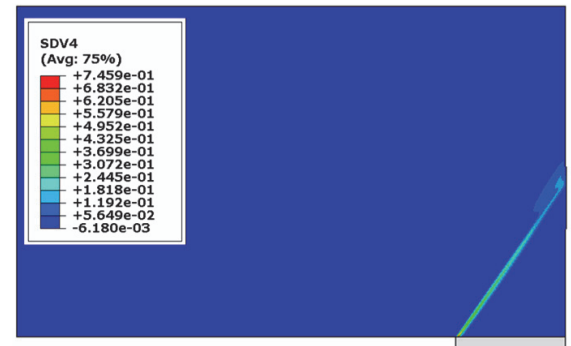

c)

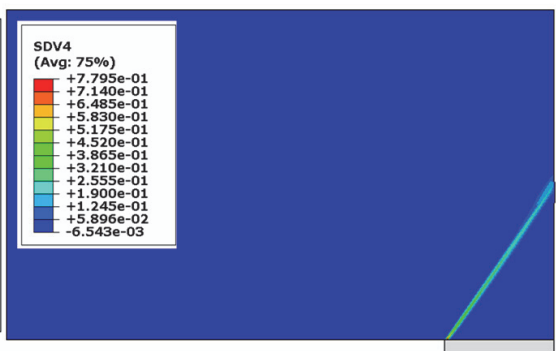

f)

Figure 4: Failure modes of the façade without openings subjected to short settlement and for the two block sizes (40x25 cm first row and $25 \times 12 \mathrm{~cm}$ second row). (a), (d): RBLA non-associative solution with no friction on vertical contacts (Type A); (b), (e): RBLA associative solution with friction on vertical contacts (Type B); (c), (f): FEA associative solutions.

\section{The façade without openings}

The first case study consists in the façade with no openings described in the previous section. The two block stone types are adopted with both the numerical models. In the case of rigid block model, when a 40x $25 \mathrm{~cm}$ block sizes (corresponding to $\mu_{b}=1.25$ for the FEA) is used, the model is made by an assemblage of 2425 rigid blocks and 28684 contact points, while, when a $25 \times 12 \mathrm{~cm}$ block size (corresponding to $\mu_{b}=0.96$ for the FEA) is adopted, the model consists of 8050 blocks and 95800 contact points. For the FEA, the masonry panel is discretized by 10720 triangular shell elements. 
The masonry wall is involved in a short, a medium and a long settlement. In the case of rigid block model, both the vertical contact cases described in the previous section are considered: the case with the same friction behaviour for the vertical and the horizontal interfaces and the case where the vertical contacts have a friction coefficient equal to zero.

Fig. 4 shows the failure mechanisms derived from the simulation with the RBLA and the principal plastic strain pattern at failure for FEA, for both the block typologies, in the case of short settlement. According to [25], as results of all the numerical simulations only the lower part of the façade over the moving support is involved in the settlement showing a local failure mechanism. For the RBLA, in the case of 'Type A' contact interfaces, the failure mechanism is characterized by a slight more localized fracture than for the 'Type B' contact interfaces. The continuous FEA solution is in good accordance with the discrete one. The adoption of different block dimensions, in this specific case, involved only small changes in failure mechanisms.

Tabs. 1, 2, 3 collect the values of vertical reaction at failure at the base of the masonry structure involved in the settlement for both the numerical models in the case of short, medium and long settlement, respectively. In the same Table, the CPU time for the analyses are reported. It is worth noting that, in order to compare the CPU time, all the analyses were carried out on the same hardware, that is using a 4.0 GHz Intel Core i7-6700 k Processor with $32.0 \mathrm{~GB}$ of RAM and, in the case of finite element path-following analysis, the CPU time for a single step analysis is expressed.

\begin{tabular}{|c|c|c|c|c|c|c|c|c|}
\hline \multirow[t]{2}{*}{$\begin{array}{c}\text { Block } \\
\text { size }[\mathrm{cm}]\end{array}$} & \multirow[t]{2}{*}{$\stackrel{\varrho}{\varrho}\left[\mathrm{kN} / \mathrm{m}^{3}\right]$} & \multirow[t]{2}{*}{$\begin{array}{l}\mu \\
{[-]}\end{array}$} & \multicolumn{2}{|c|}{$\begin{array}{l}\mathrm{RB} \text { with no friction on } \\
\text { vertical contacts (Type A) }\end{array}$} & \multicolumn{2}{|c|}{$\begin{array}{c}\mathrm{RB} \text { with friction on } \\
\text { vertical contacts (Type B) }\end{array}$} & \multicolumn{2}{|c|}{ Finite Element Model } \\
\hline & & & $\begin{array}{c}\text { fs } \\
{[\mathrm{kN}]}\end{array}$ & $\begin{array}{l}\text { CPU Time } \\
{[\mathrm{s}]}\end{array}$ & $\begin{array}{c}\text { fs } \\
{[\mathrm{kN}]}\end{array}$ & $\begin{array}{l}\text { CPU Time } \\
{[\mathrm{s}]}\end{array}$ & $\begin{array}{l}\text { fs } \\
{[\mathrm{kN}]}\end{array}$ & $\begin{array}{l}\text { CPU Time } \\
{[\mathrm{s}]}\end{array}$ \\
\hline $40 \times 25$ & \multirow{2}{*}{16} & \multirow{2}{*}{0.6} & 83.79 & 17.68 & 66.30 & 25.48 & 88.43 & 81.50 \\
\hline $25 \times 12$ & & & 64.46 & 130.87 & 55.20 & 134.77 & 81.03 & $77, .70$ \\
\hline
\end{tabular}

Table 1: Base reaction and CPU Time in the case of the façade without openings subjected to short settlements.

\begin{tabular}{|c|c|c|c|c|c|c|c|c|}
\hline \multirow[t]{2}{*}{$\begin{array}{l}\text { Block } \\
\text { size }[\mathrm{cm}]\end{array}$} & \multirow[t]{2}{*}{$\stackrel{\varrho}{\varrho}\left[\mathrm{kN} / \mathrm{m}^{3}\right]$} & \multirow[t]{2}{*}{$\begin{array}{l}\mu \\
{[-]}\end{array}$} & \multicolumn{2}{|c|}{$\begin{array}{l}\text { RB with no friction on } \\
\text { vertical contacts (Type A) }\end{array}$} & \multicolumn{2}{|c|}{$\begin{array}{c}\text { RB with friction on } \\
\text { vertical contacts (Type B) }\end{array}$} & \multicolumn{2}{|c|}{ Finite Element Model } \\
\hline & & & $\begin{array}{c}\text { fs } \\
{[\mathrm{kN}]}\end{array}$ & $\begin{array}{l}\text { CPU Time } \\
{[\mathrm{s}]}\end{array}$ & $\begin{array}{c}\mathrm{fs} \\
{[\mathrm{kN}]}\end{array}$ & $\begin{array}{l}\text { CPU Time } \\
{[\mathrm{s}]}\end{array}$ & $\begin{array}{l}\text { fs } \\
{[\mathrm{kN}]}\end{array}$ & $\begin{array}{l}\text { CPU Time } \\
{[\mathrm{s}]}\end{array}$ \\
\hline $40 \times 25$ & \multirow{2}{*}{16} & \multirow{2}{*}{0.6} & 515.18 & 50.75 & 428.79 & 7.95 & 532.01 & 70.09 \\
\hline $25 \times 12$ & & & 488.32 & 613.26 & 423.99 & 54.24 & 534.11 & 71.30 \\
\hline
\end{tabular}

Table 2: Base reaction and CPU Time in the case of the façade without openings subjected to medium settlements.

\begin{tabular}{|c|c|c|c|c|c|c|c|c|}
\hline \multirow[t]{2}{*}{$\begin{array}{c}\text { Block } \\
\text { size }[\mathrm{cm}]\end{array}$} & \multirow[t]{2}{*}{$\stackrel{\varrho}{\left[\mathrm{kN} / \mathrm{m}^{3}\right]}$} & \multirow[t]{2}{*}{$\begin{array}{c}\mu \\
{[-]}\end{array}$} & \multicolumn{2}{|c|}{$\begin{array}{c}\mathrm{RB} \text { with no friction on } \\
\text { vertical contacts (Type } \mathrm{A} \text { ) }\end{array}$} & \multicolumn{2}{|c|}{$\begin{array}{c}\text { RB with friction on } \\
\text { vertical contacts (Type B) }\end{array}$} & \multicolumn{2}{|c|}{ Finite Element Model } \\
\hline & & & $\begin{array}{c}\text { fs } \\
{[\mathrm{kN}]}\end{array}$ & $\begin{array}{l}\text { CPU Time } \\
{[\mathrm{s}]}\end{array}$ & $\begin{array}{c}\text { fs } \\
{[\mathrm{kN}]}\end{array}$ & $\begin{array}{l}\text { CPU Time } \\
{[\mathrm{s}]}\end{array}$ & $\begin{array}{c}\text { fs } \\
{[\mathrm{kN}]}\end{array}$ & $\begin{array}{l}\text { CPU Time } \\
{[\mathrm{s}]}\end{array}$ \\
\hline $40 \times 25$ & \multirow{2}{*}{16} & \multirow{2}{*}{0.6} & 892.30 & 23.94 & 753.70 & 8.72 & 909,83 & 78.04 \\
\hline $25 \times 12$ & & & 847.33 & 652.83 & 767.98 & 52.20 & 909.68 & 75.03 \\
\hline
\end{tabular}

Table 3: Base reaction and CPU Time in the case of the façade without openings subjected to long settlements.

In Figs. 5-7-9, the evolution of the vertical reaction at the base of the masonry structure, during the path-following analysis, versus the vertical displacement applied to the movable block for the FEA is represented using a semi-logarithmic scale, in the case of short, medium and long settlements, respectively. In the same figures, the results in term of vertical reaction for the RBLA are also reported. For the RBLA, when the friction on the vertical contact interfaces is not involved, the value of the reaction at failure is greater than that provided by the same non-linear model when the friction in the vertical contacts interfaces is involved. It is worth noting that the value for the vertical reaction provided by the homogenized FEA is an upper bound for both the solution provided by the RBLA. This is not surprising as the FEA is based on the homogenization theory, where the characteristic size of the block (its height or width) has to be small enough when compared with the 
characteristic length of the problem, such as the wall's height or width [23]. A slight difference in terms of reaction at the base of the masonry panel in case of the two adopted block typologies is observed for both the model, to 40x 25 block size corresponds a slight greater reaction at failure than that corresponding to the case of $25 \times 12$ block size.
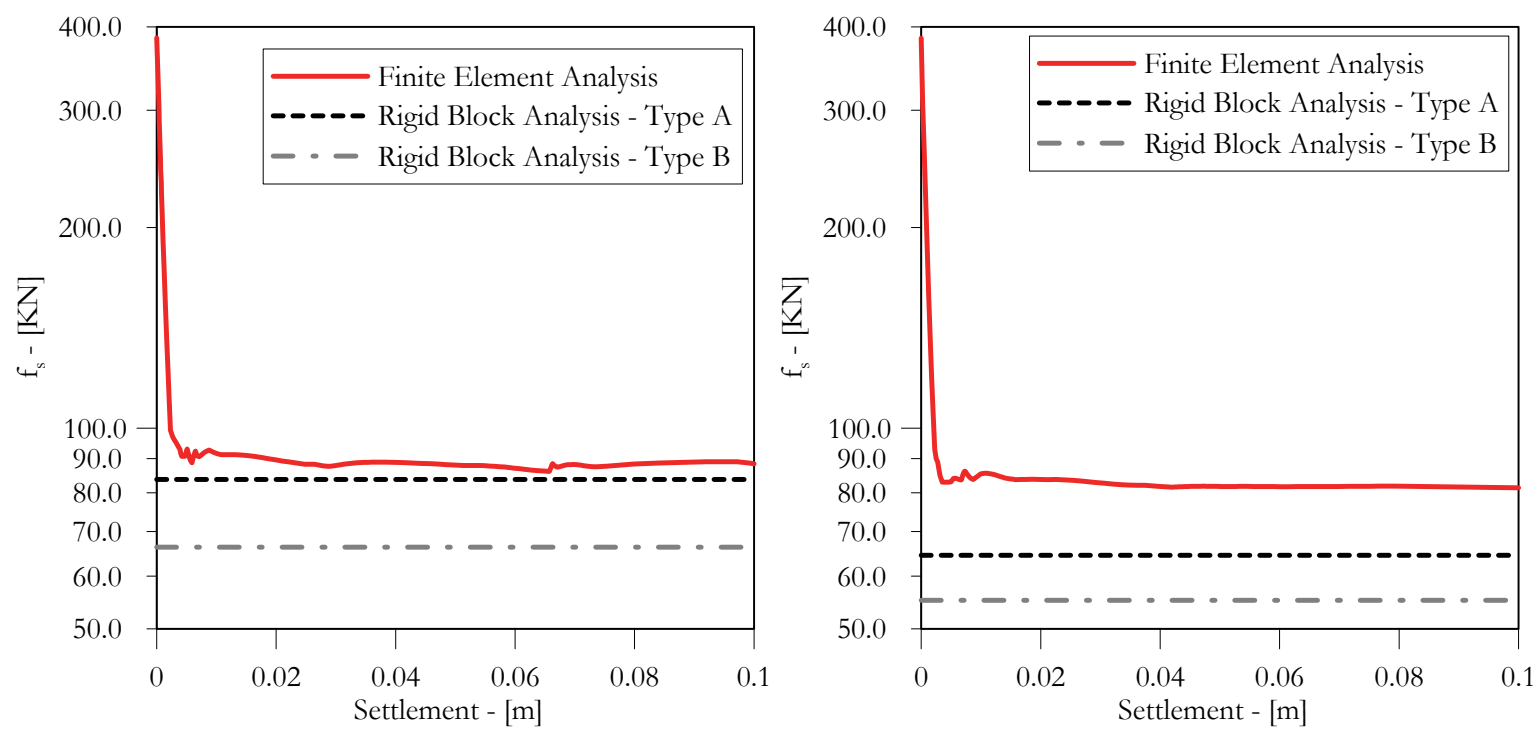

Figure 5: Evolution of the reaction at the base of the masonry structure involved in the settlement vs. imposed displacement in the case of the façade without openings subjected to short settlement: 40x25 block size (a) and 25x12 block size (b).

Fig.6 shows the failure mechanisms derived from the simulation with the RBLA and the principal plastic strain pattern at failure for FEA for both the block sizes considered, in the case of medium settlement. As observed in Fig.6 a-c-d-f), the upper part of the wall shows a vertical crack while in the lower part a diagonal crack develops. This failure pattern is a typical global failure mode, derived from the combination of displacements and rotations of the block units, for the medium settlement [25]. It is worth noting that both the models are able to capture this key element in the masonry behaviour with the only exception for the RBLA in the case of the 'type B' contact interface, where a more local behaviour is returned from the numerical analysis. Also in this case, the block size does not change significantly the shape of mechanism, for both the numerical models.

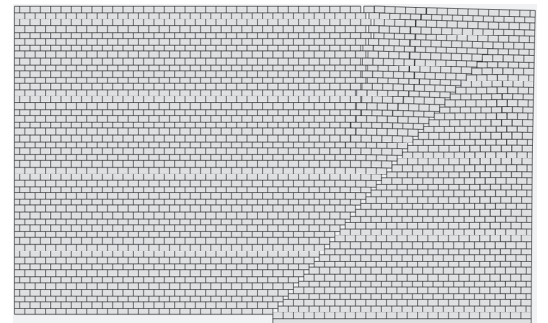

a)

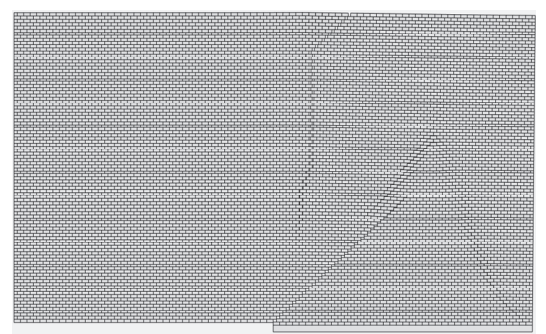

d)

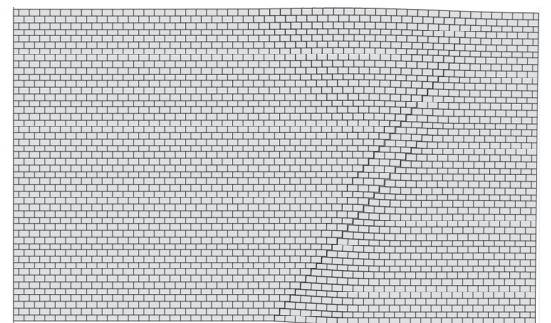

b)

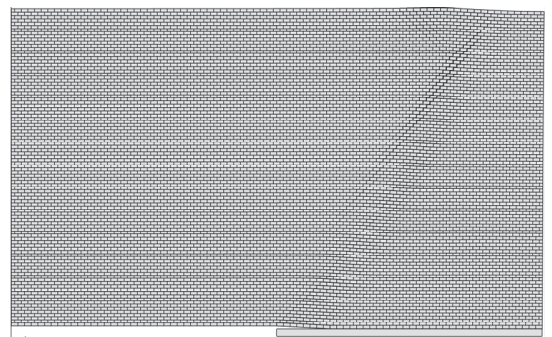

e)
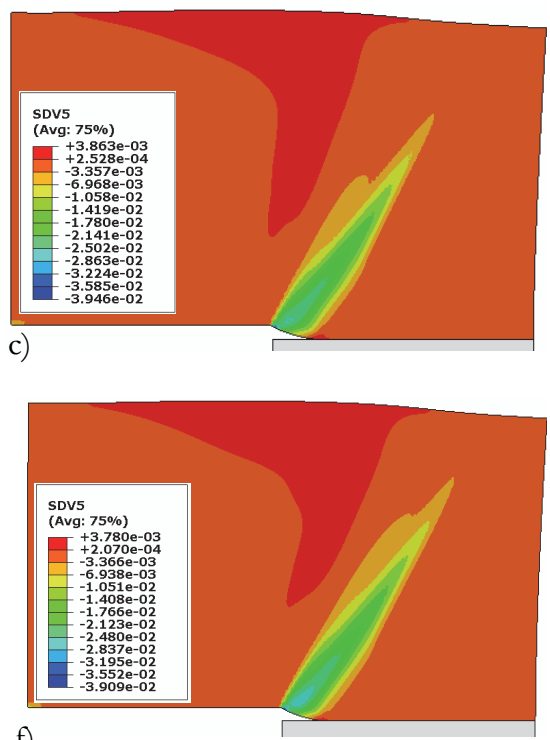

f)

Figure 6: Failure modes of the façade without openings subjected to medium settlement and for the two block sizes (40x25 cm first row and 25x12 cm second row). (a), (d): RBLA non-associative solution with no friction on vertical contacts (Type A); (b), (e): RBLA associative solution with friction on vertical contacts (Type B); (c), (f): FEA associative solutions. 

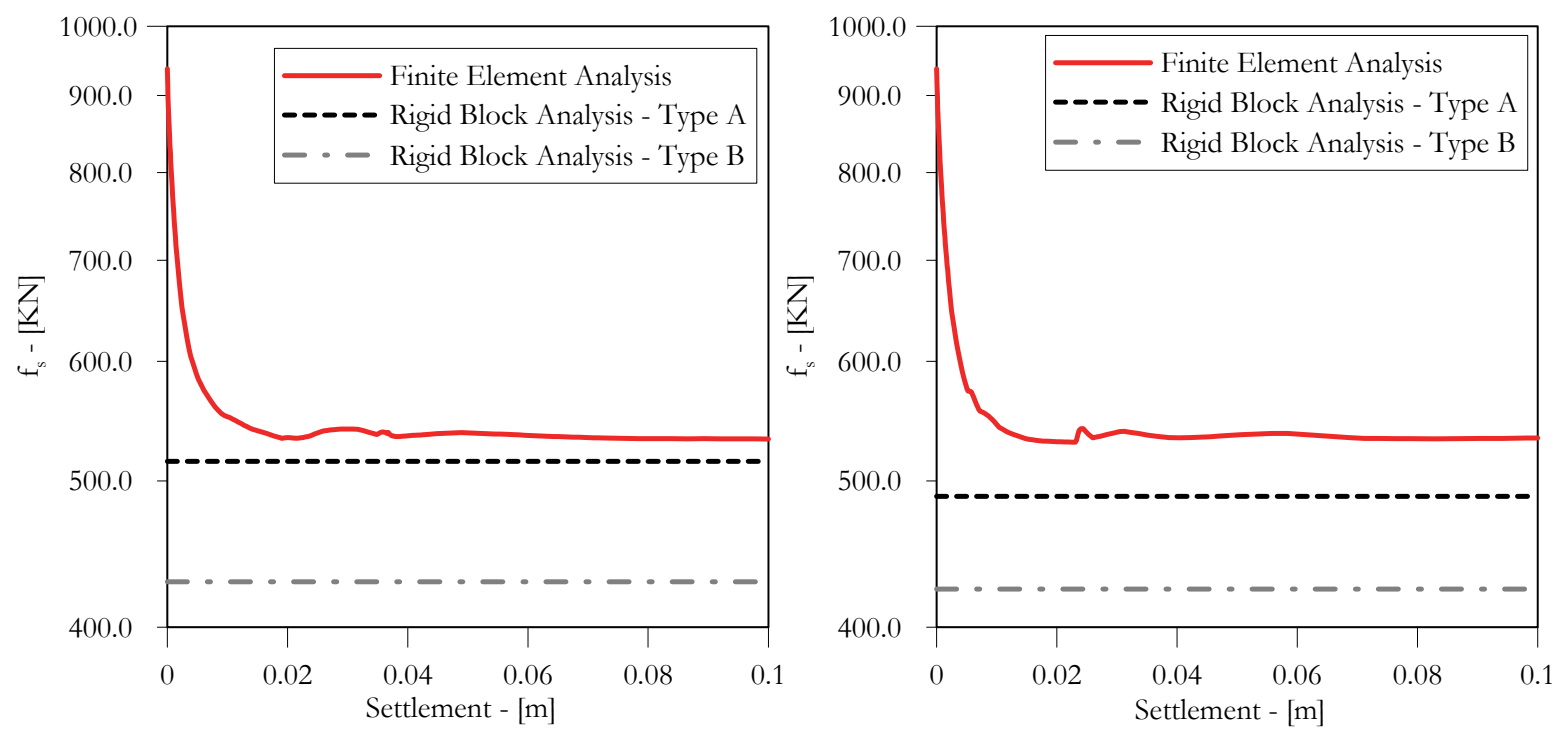

Figure 7: Evolution of the reaction at the base of the masonry structure involved in the settlement vs imposed displacement in the case of the façade without openings subjected to medium settlement: 40x25 block size (a) and 25x12 block size (b).

Fig. 8 shows the failure mechanisms derived from the simulation with the RBLA and the principal plastic strain pattern at failure for FEA for both the block typologies in the case of long settlement. All numerical simulations provide a failure pattern with a diagonal crack developing from the left end side of the moving support up to the upper edge of the wall dividing the masonry wall into two parts, except to for the results obtained from the RBLA in the case of contact type A and 25x12 block size (Fig.8d), where a more vertical crack is observed at failure. Really, this last failure mode should be expected according to [25], and such a discrepancy is probably due to the simple way adopted for the simulation of the ground settlement.

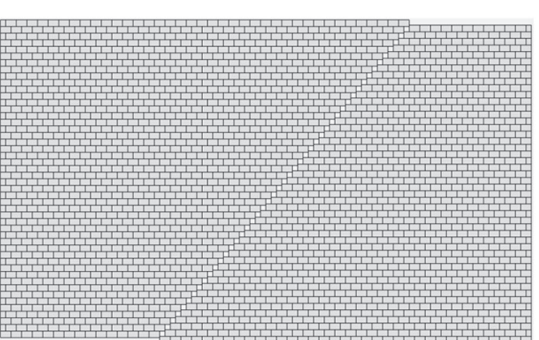

a)

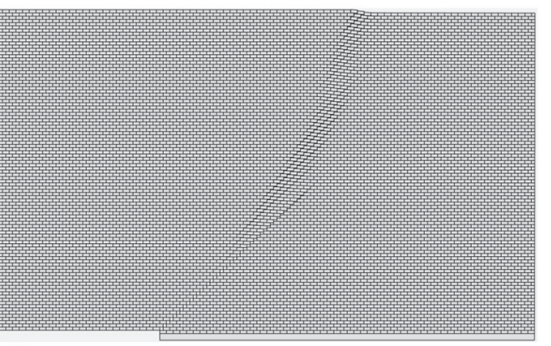

d)

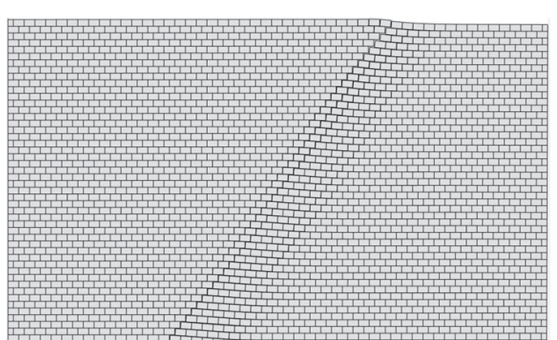

b)

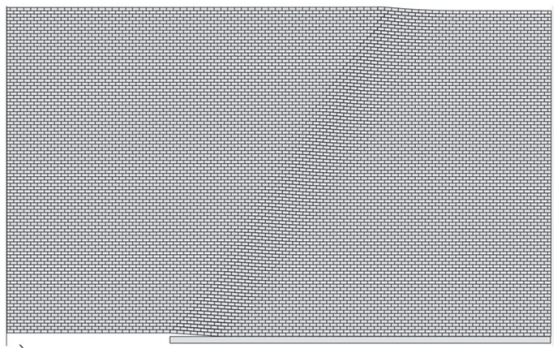

e)
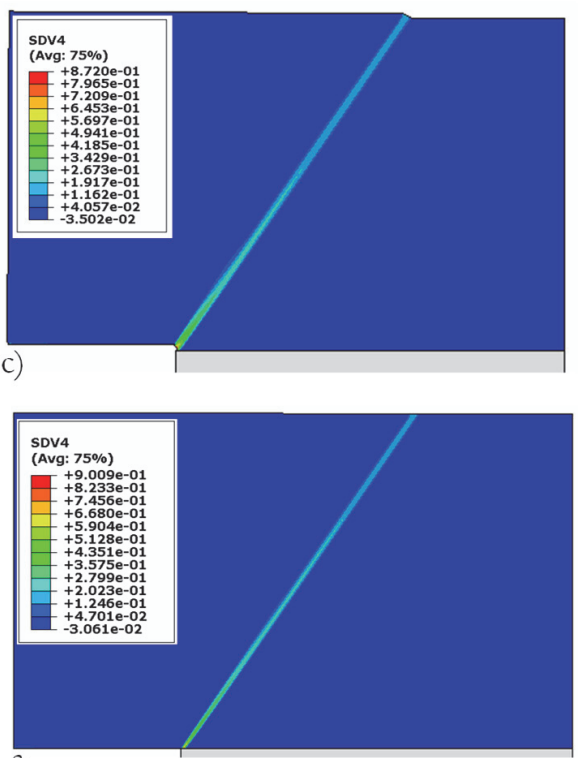

f)

Figure 8: Failure modes of the façade without openings subjected to long settlement and for the two block sizes (40x25 cm first row and $25 \times 12 \mathrm{~cm}$ second row). (a), (d): RBLA non-associative solution with no friction on vertical contacts (Type A); (b), (e): RBLA associative solution with friction on vertical contacts (Type B); (c), (f): FEA associative solutions.

In general, it should be noted that, in contrast to the homogenization assumptions, where closer results are expected when the size of the rigid blocks is small, the analyses show a better convergence of FEA and RBLA when larger blocks are used. 
It should be also noted that FEA results are closer to the Type A behaviour of the rigid block model, although the same friction coefficient is used in FEA model for horizontal and vertical contacts. On one side, this discrepancy can be ascribed to the different aspect ratios, i.e. the height to width ratio of the blocks, which were adopted for the two block dimensions. This might have affected the expected convergence behaviour, which instead should be observed when the same aspect ratio is used. Moreover, slightly different failure mechanisms were observed in the rigid block model when Type A and Type $\mathrm{B}$ behaviours are considered for sliding failure.

A set of numerical analyses to consider the effects of distributed loads corresponding to the floors were also carried out. The loads were applied on courses at 6.00 and $12.00 \mathrm{~m}$ height and a magnitude of $24.0 \mathrm{kN} / \mathrm{m}$ was considered. The results showed that the failure mechanisms are not affected by the floor loads. As for the reactions at the moving supports, the comparison of $\mathrm{RB}$ and $\mathrm{FE}$ models showed a similar response to those presented for previous cases, with different magnitudes associated to the imposed loads.

\section{The facade with openings}

The second case study is represented by the façade with openings on the front, above described, subject to settlements. Also in this case, the same two block typologies are used in this application. In the case of rigid block model, when a $40 x 25$ $\mathrm{cm}$ block size is used, the model is made by an assemblage of 2148 rigid blocks and 24608 contact points, while, when a $25 \times 12 \mathrm{~cm}$ block size is adopted, the model consists of 7156 blocks and 83520 contact points. For the FEA model, the masonry panel is discretized by 7446 shell elements.

The masonry walls are involved, also in this case, in a short, a medium and a long settlement and, for rigid block model, both the vertical contact type, $\mathrm{A}$ and $\mathrm{B}$, are considered.

Fig.10 shows the failure mechanisms derived from the simulation with the RBLA and the principal plastic strain pattern at failure for FE analyses for both the block typologies in the case of short settlement. The presence of the openings changes the structural response to the short settlement. The part of the façade involved into the mechanism at failure is the portion of the wall over the moving support with the development of cracks above the two openings.

As observed from the results, the mechanism is not strong influenced by the contact type adopted and a good matching between FE and RB models can be observed. Further the size block only affects in a slight way the results.
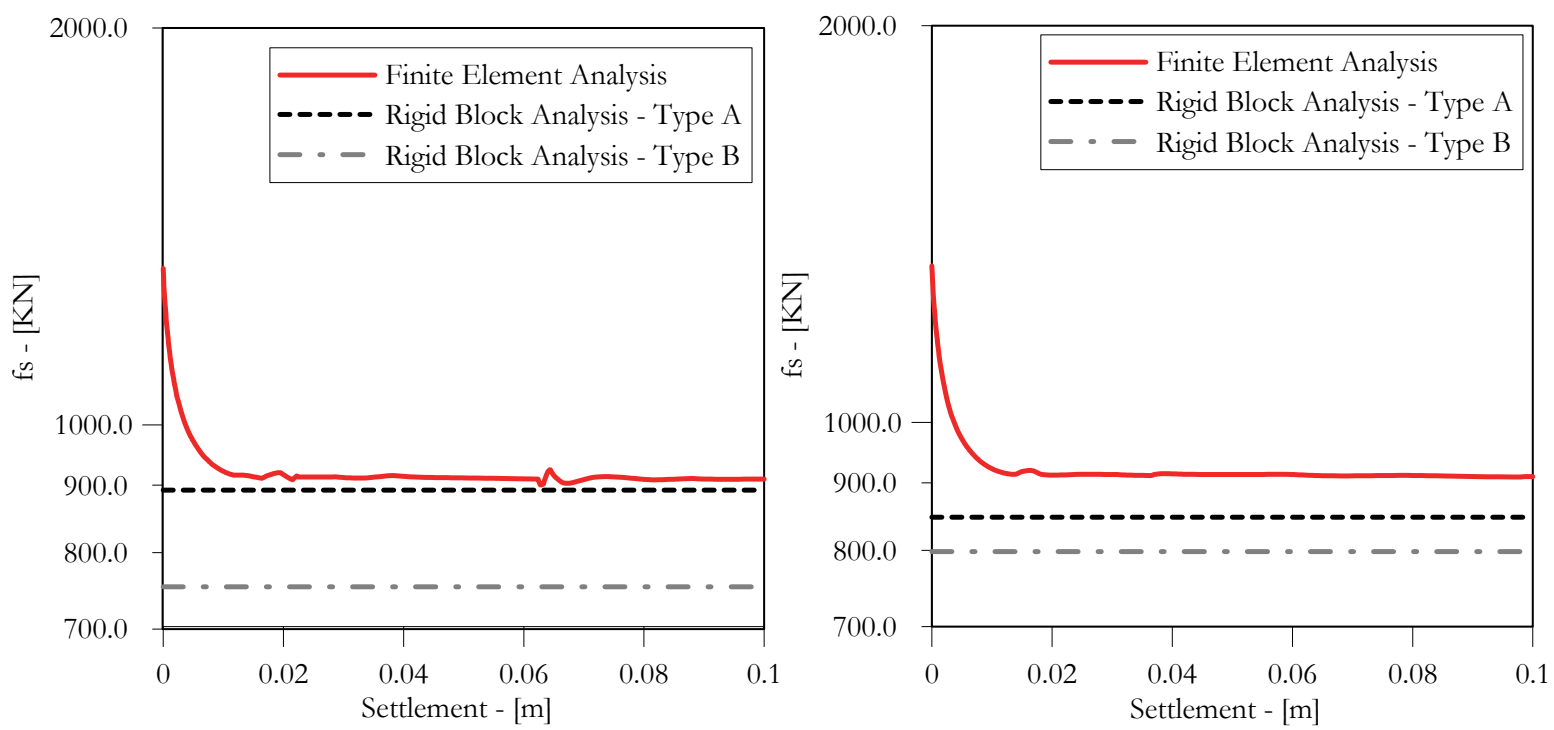

Figure 9: Evolution of the reaction at the base of the masonry structure involved in the settlement vs imposed displacement in the case of the façade without openings subjected to long settlement: 40x25 block size (a) and 25x12 block size (b).

Tabs. 4, 5, 6 collect the values of vertical reaction at failure at the base of the masonry structure involved in the settlement for both the numerical models in the case of short, medium and long settlement, respectively. In the same Table, the CPU time for the analyses are reported. 


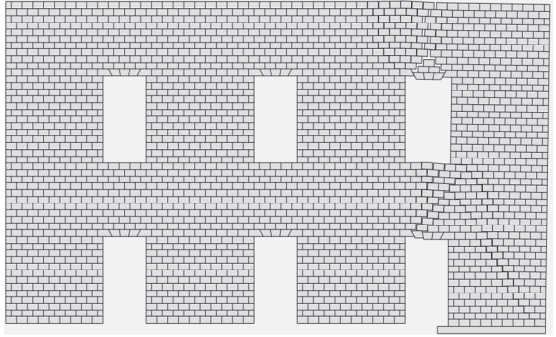

a)

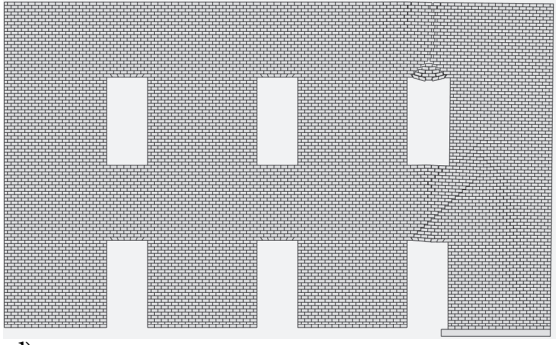

d)

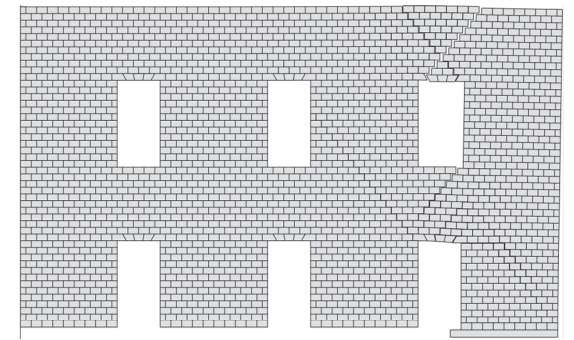

b)

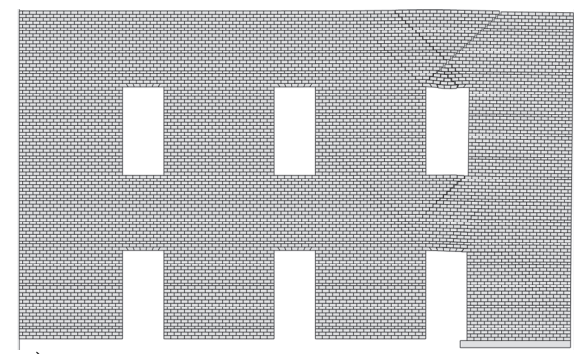

e)

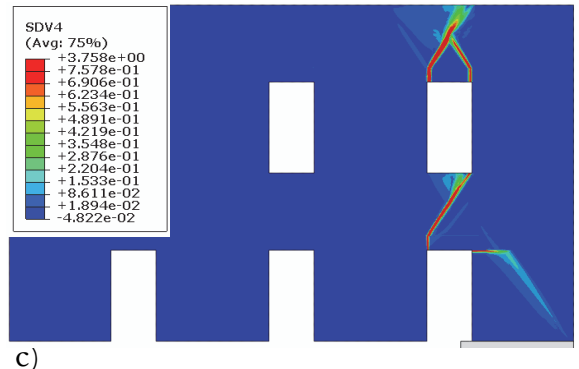

c)

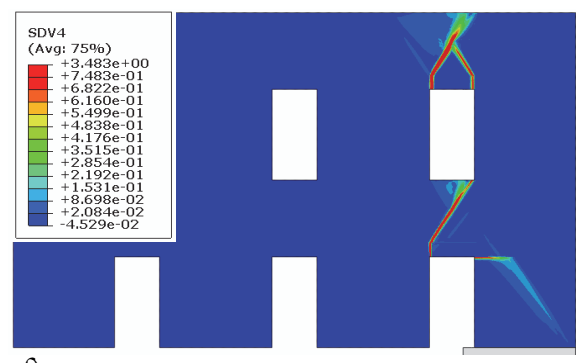

f)

: Failure modes of the façade with openings subjected to short settlement and for the two block sizes (40x $25 \mathrm{~cm}$ first row and $25 \times 12 \mathrm{~cm}$ second row). (a), (d): RBLA non-associative solution with no friction on vertical contacts (Type A); (b), (e): RBLA associative solution with friction on vertical contacts (Type B); (c), (f): FE associative solutions.

\begin{tabular}{|c|c|c|c|c|c|c|c|c|}
\hline \multirow[t]{2}{*}{$\begin{array}{c}\text { Block } \\
\text { size }[\mathrm{cm}]\end{array}$} & \multirow[t]{2}{*}{$\stackrel{\varrho}{\varrho}$} & \multirow[t]{2}{*}{$\begin{array}{c}\mu \\
{[-]}\end{array}$} & \multicolumn{2}{|c|}{$\begin{array}{l}\text { RB with no friction on } \\
\text { vertical contacts (Type A) }\end{array}$} & \multicolumn{2}{|c|}{$\begin{array}{c}\mathrm{RB} \text { with friction on } \\
\text { vertical contacts (Type } \mathrm{B} \text { ) }\end{array}$} & \multicolumn{2}{|c|}{ Finite Element Model } \\
\hline & & & $\begin{array}{c}\mathrm{fs} \\
{[\mathrm{kN}]}\end{array}$ & $\begin{array}{l}\text { CPU Time } \\
{[\mathrm{s}]}\end{array}$ & $\begin{array}{c}\text { fs } \\
{[\mathrm{kN}]}\end{array}$ & $\begin{array}{l}\text { CPU Time } \\
{[\mathrm{s}]}\end{array}$ & $\begin{array}{c}\text { fs } \\
{[\mathrm{kN}]}\end{array}$ & $\begin{array}{l}\text { CPU Time } \\
{[\mathrm{s}]}\end{array}$ \\
\hline $40 \times 25$ & \multirow{2}{*}{16} & \multirow{2}{*}{0.6} & 278.46 & 21.83 & 259.60 & 4.03 & 288.31 & 87.32 \\
\hline $25 \times 12$ & & & 273.66 & 397.06 & 251.85 & 29.30 & 279.41 & 88.51 \\
\hline
\end{tabular}

Table 4: Base reaction and CPU Time in the case of the façade with openings subjected to short settlements.

\begin{tabular}{|c|c|c|c|c|c|c|c|c|}
\hline \multirow[t]{2}{*}{$\begin{array}{c}\text { Block } \\
\text { size }[\mathrm{cm}]\end{array}$} & \multirow[t]{2}{*}{$\stackrel{\varrho}{\varrho}\left[\mathrm{kN} / \mathrm{m}^{3}\right]$} & \multirow[t]{2}{*}{$\begin{array}{l}\mu \\
{[-]}\end{array}$} & \multicolumn{2}{|c|}{$\begin{array}{l}\text { RB with no friction on } \\
\text { vertical contacts (Type A) }\end{array}$} & \multicolumn{2}{|c|}{$\begin{array}{c}\mathrm{RB} \text { with friction on } \\
\text { vertical contacts (Type } \mathrm{B} \text { ) }\end{array}$} & \multicolumn{2}{|c|}{ Finite Element Model } \\
\hline & & & $\begin{array}{c}\mathrm{fs} \\
{[\mathrm{kN}]}\end{array}$ & $\begin{array}{l}\text { CPU Time } \\
{[\mathrm{s}]}\end{array}$ & $\begin{array}{c}\text { fs } \\
{[\mathrm{kN}]}\end{array}$ & $\begin{array}{l}\text { CPU Time } \\
{[\mathrm{s}]}\end{array}$ & $\begin{array}{c}\text { fs } \\
{[\mathrm{kN}]}\end{array}$ & $\begin{array}{c}\text { CPU Time } \\
{[\mathrm{s}]}\end{array}$ \\
\hline $40 \times 25$ & \multirow{2}{*}{16} & \multirow{2}{*}{0.6} & 638.05 & 47.45 & 604.67 & 4.42 & 668.01 & 85.31 \\
\hline $25 \times 12$ & & & 644.73 & 233.12 & 610.34 & 40.43 & 665.06 & 89.21 \\
\hline
\end{tabular}

Table 5: Base reaction and CPU Time in the case of the façade with openings subjected to medium settlements.

\begin{tabular}{|c|c|c|c|c|c|c|c|c|}
\hline \multirow[t]{2}{*}{$\begin{array}{c}\text { Block } \\
\text { size }[\mathrm{cm}]\end{array}$} & \multirow[t]{2}{*}{$\stackrel{\varrho}{\varrho}$} & \multirow[t]{2}{*}{$\begin{array}{c}\mu \\
{[-]}\end{array}$} & \multicolumn{2}{|c|}{$\begin{array}{l}\text { RB with no friction on } \\
\text { vertical contacts (Type A) }\end{array}$} & \multicolumn{2}{|c|}{$\begin{array}{c}\mathrm{RB} \text { with friction on } \\
\text { vertical contacts (Type } \mathrm{B} \text { ) }\end{array}$} & \multicolumn{2}{|c|}{ Finite Element Model } \\
\hline & & & $\begin{array}{c}\mathrm{fs} \\
{[\mathrm{kN}]}\end{array}$ & $\begin{array}{l}\text { CPU Time } \\
{[\mathrm{s}]}\end{array}$ & $\begin{array}{c}\text { fs } \\
{[\mathrm{kN}]}\end{array}$ & $\begin{array}{l}\text { CPU Time } \\
{[\mathrm{s}]}\end{array}$ & $\begin{array}{c}\text { fs } \\
{[\mathrm{kN}]}\end{array}$ & $\begin{array}{l}\text { CPU Time } \\
{[\mathrm{s}]}\end{array}$ \\
\hline $40 \times 25$ & \multirow{2}{*}{16} & \multirow{2}{*}{0.6} & 873.30 & 14.04 & 734.92 & 5.50 & 890.31 & 81.25 \\
\hline $25 \times 12$ & & & 808.60 & 575.01 & 745.14 & 43.42 & 877.51 & 78.61 \\
\hline
\end{tabular}

Table 6: Base reaction and CPU Time in the case of the façade with openings subjected to long settlements. 
In Fisg.11-13-15, the evolution of the vertical reaction at the base of the masonry structure, during the path-following analysis, versus the vertical displacement applied to the movable block for the FE model is represented using a semilogarithmic scale, in the case of short, medium and long settlements, respectively. In the same figures, the results in term of vertical reaction for the RBLA are also reported. The same considerations for the case of façade without openings are still valid: for the RBLA, when the friction on the vertical contact interfaces is not involved, the value of the reaction at the base of the movable support is greater than that provided by the same non-linear model when the friction in the vertical contacts interfaces is involved; when RBLA and FEA are compared in term of vertical reaction at the base of the masonry panel, the value for the reaction provided by the homogenized FEA model is an upper bound for values provided by the RBLA.
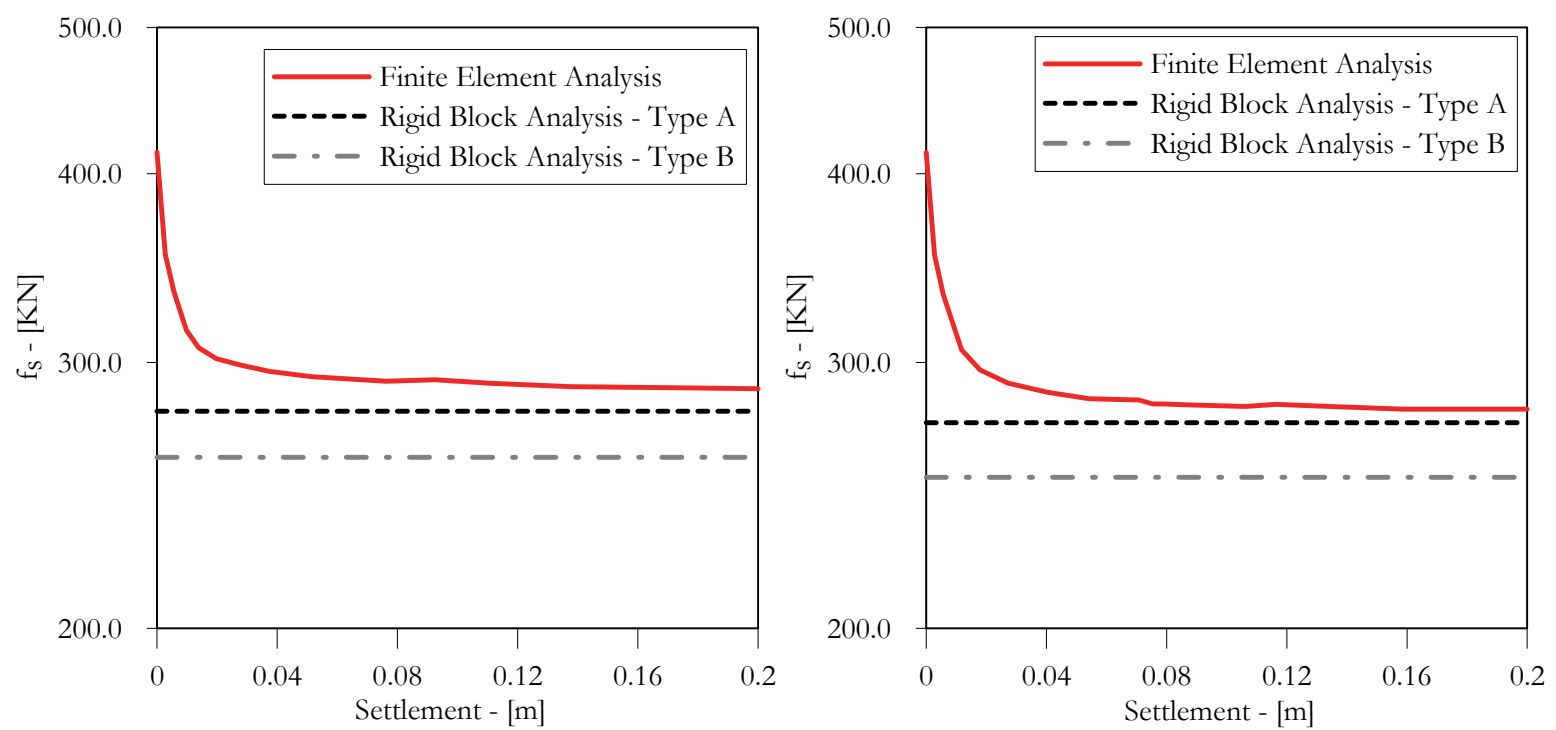

Figure 11: Evolution of the reaction at the base of the masonry structure involved in the settlement vs imposed displacement in the case of the façade with openings subjected to short settlement: 40x25 block size (a) and 25x12 block size (b).

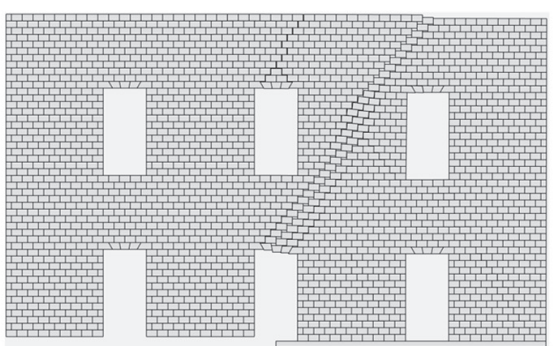

a)

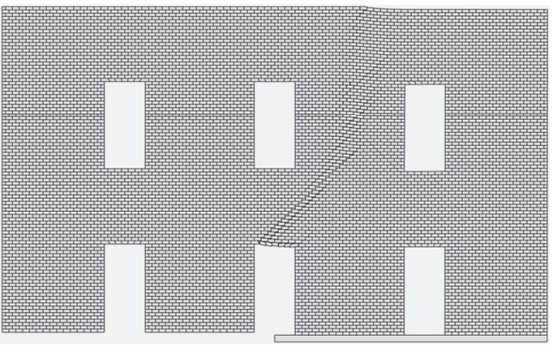

d)

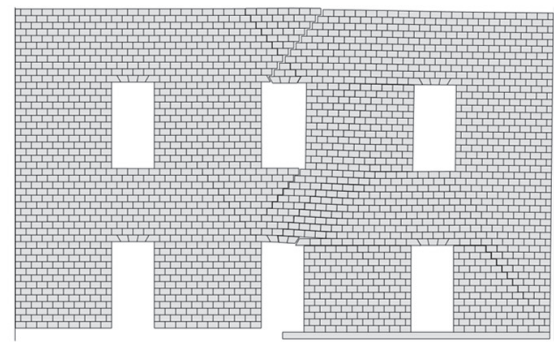

b)

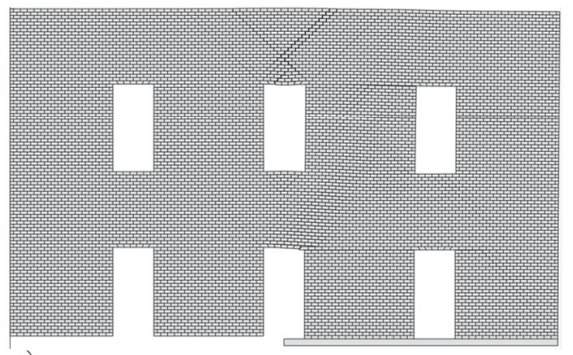

e)

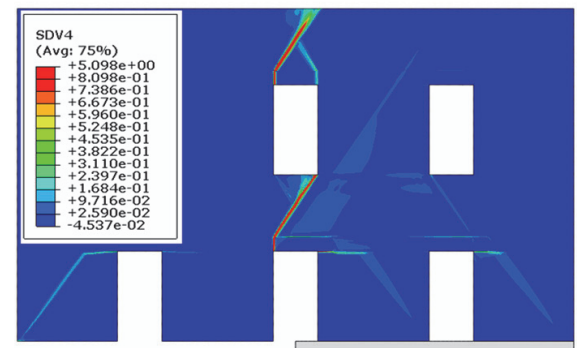

c)

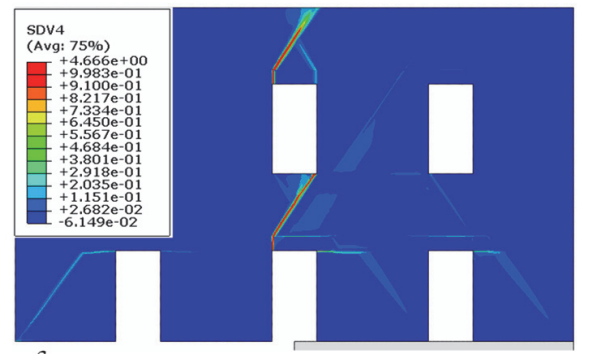

f)

Figure 12: Failure modes of the façade with openings subjected to medium settlement and for the two block sizes $(40 \mathrm{x} 25 \mathrm{~cm}$ first row and 25x12 cm second row). (a), (d): RBLA non-associative solution with no friction on vertical contacts (Type A); (b), (e): RBLA associative solution with friction on vertical contacts (Type B); (c), (f): FEA associative solutions. 
Fig.12 shows the failure mechanisms derived from the simulation with the RBLA and the principal plastic strain pattern at failure for FEA for both the block typologies in the case of medium settlement. The failure pattern is mainly characterized by a diagonal crack above the two central openings, in the case of RBLA with contact type B and FEA. When contact type A for RBLA is adopted a diagonal crack above the central opening at the first floor develops up to the second floor. The block typology affects only in a slight way the results: when 25x12 block size is adopted, more localized fractures than for 40x25 cm block size, develops.
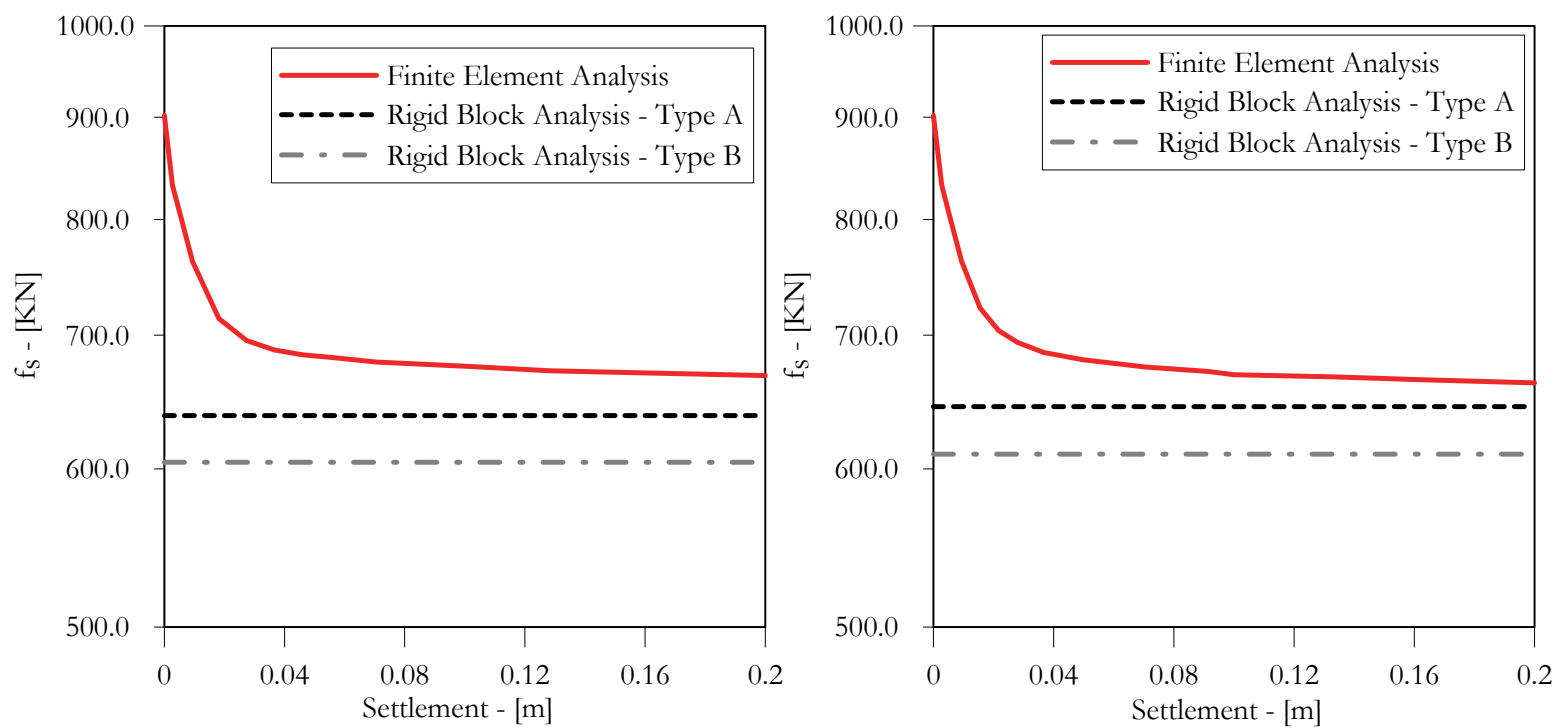

Figure 13: Evolution of the reaction at the base of the masonry structure involved in the settlement vs imposed displacement in the case of the façade with openings subjected to medium settlement: 40x25 block size (a) and 25x12 block size (b).

Finally, Fig.14 shows the failure mechanisms derived from the simulation with the RBLA and the principal plastic strain pattern at failure for FEA for both the block typologies in the case of long settlement. Failure pattern, for both RBLA and FEM, is characterized by a diagonal crack from the end side of the movable block up to central opening at the second floor and by a diagonal crack above the same opening. In this case, the size block does not affect the failure mode.

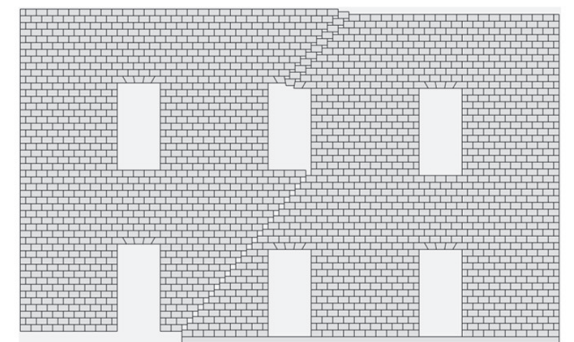

a)

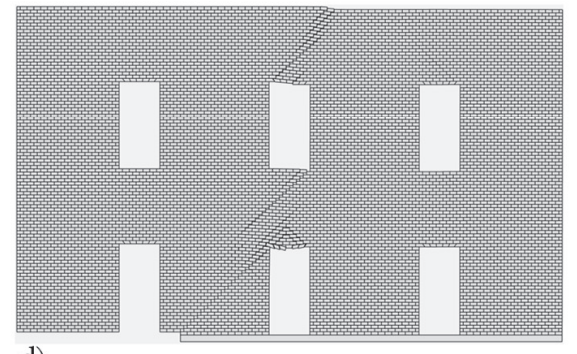

d)

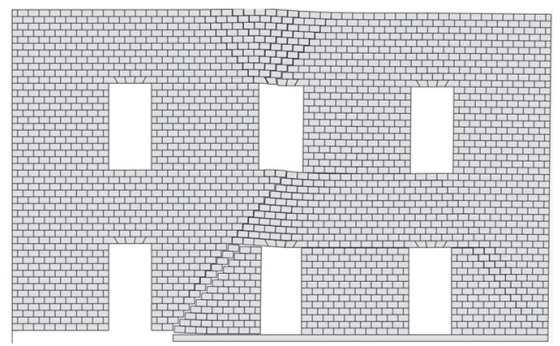

b)

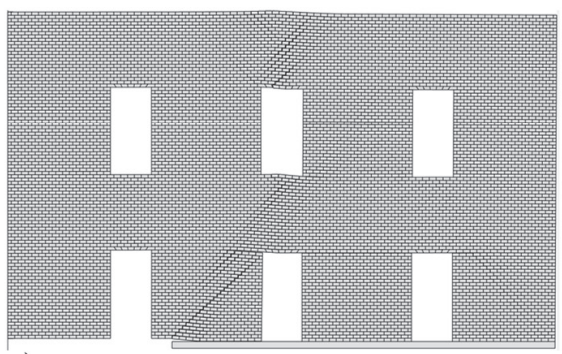

e)

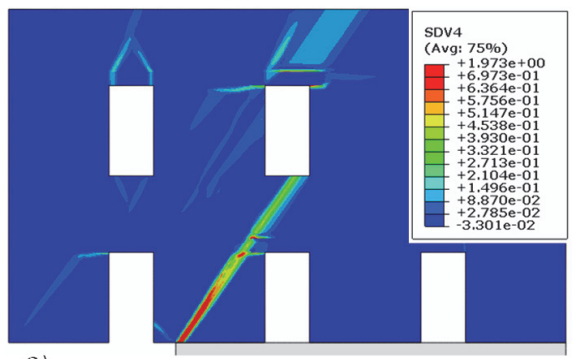

C)

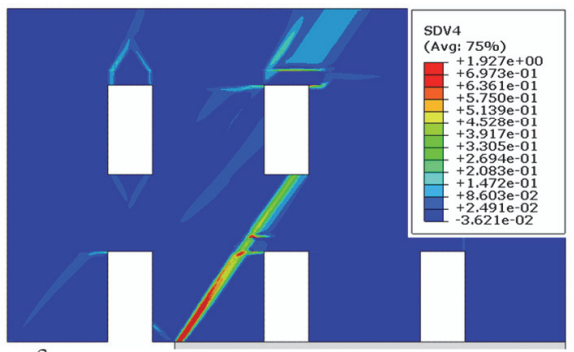

f)

Figure 14: Failure modes of the façade with openings subjected to long settlement and for the two block sizes (40x25 cm first row and 25x12 cm second row). (a), (d): RBLA non-associative solution with no friction on vertical contacts (Type A); (b), (e): RBLA associative solution with friction on vertical contacts (Type B); (c), (f): FEA associative solutions. 

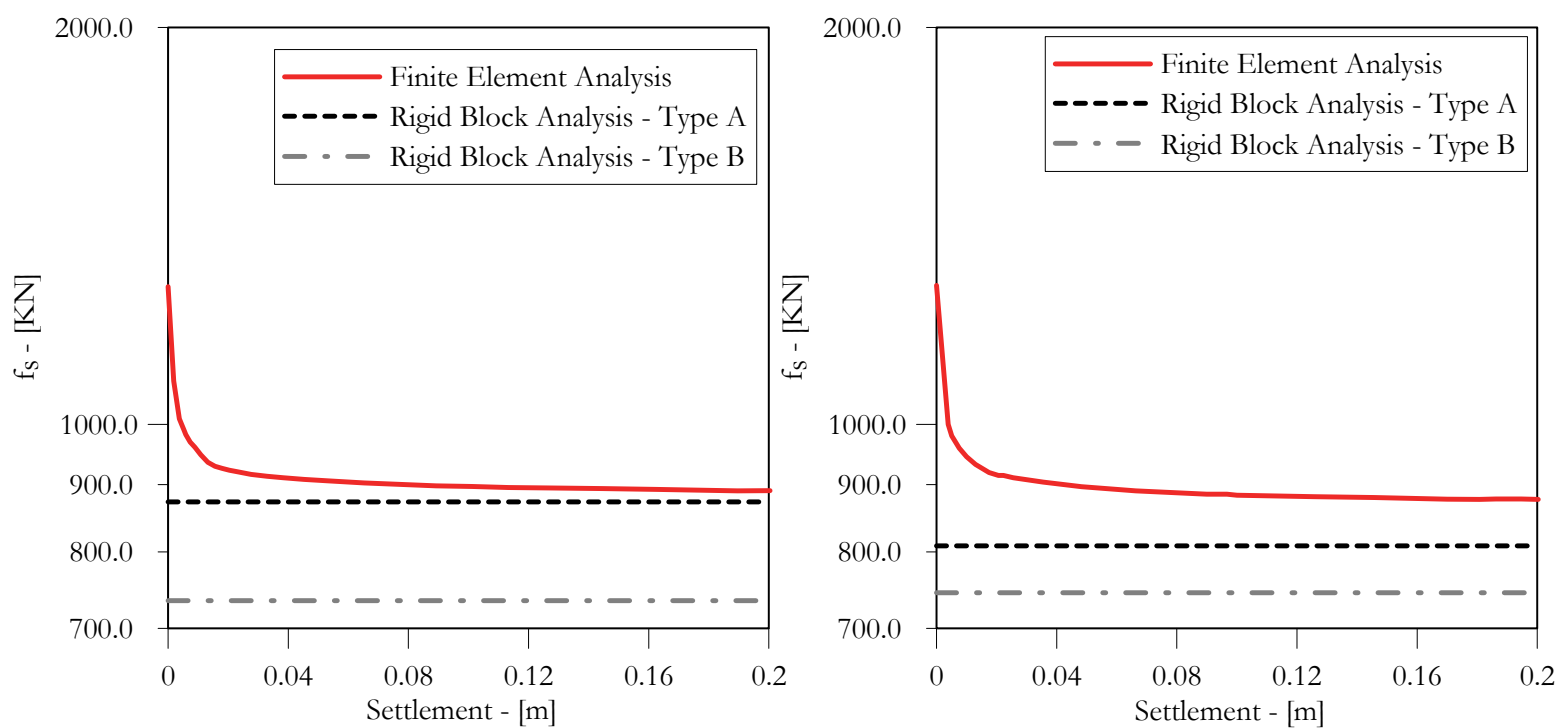

Figure 15: Reactions at the moving support in the case of the façade with openings subjected to long settlement: 40x25 block size (a) and $25 \times 12$ block size (b).

As for the effects of floor loads, also in this case we observed similar results in terms of failure modes to those obtained on the wall panel subjected to self-weight only.

Finally, in order to show the computational efficiency of the implemented modelling approaches, the CPU Time per Hertz is reported in Fig. 16 when varying the blocks number. The figure shows that the most demanding approach is represented by the RBLA - Type A model in the case of a $25 \times 12 \mathrm{~cm}$ block size (corresponding to 8050 blocks). This is due to the fact that in the case of Type A model a non-associative behaviour is assumed. In such a case, the solution of the implemented iterative procedure to obtain zero-dilatancy sliding behaviour involves larger CPU time.

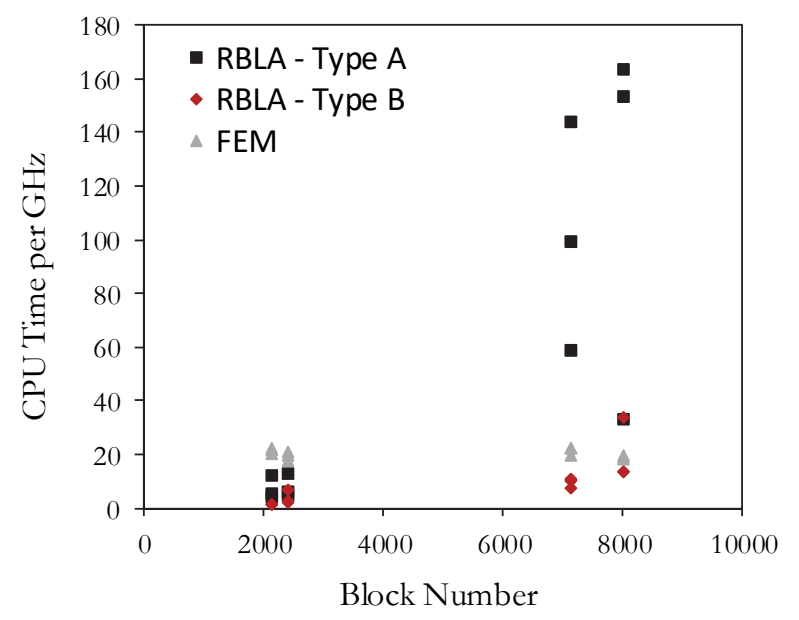

Figure 16: The effect of the block number on the CPU Time per Hertz.

\section{CONCLUSIONS}

7 he results of a comparative study on the failure pattern of historic masonry walls subjected to settlements were presented. Two numerical formulations were used in order to investigate the behaviour of masonry panels subjected to ground movements: a rigid block model based on a contact point interfaces and an elastic perfectly plastic homogenized plate model. 
The comparison showed a good agreement of the two approaches in the prediction of the failure mode and in the reduction of the reaction at the foundation that activates the failure mechanism, when varying the shape of the masonry units, the wall openings and the width of the settled area.

The analysis revealed that the failure mode is only slightly affected by the loads provided by the floors, while is strongly affected by the presence and disposition of openings and by the width of the settled area. Depending on the width of the moving support, the failure mechanism turns from local (i.e. affecting a limited part of the wall) to global (i.e. interesting all the wall). The numerical results of both approaches are in a good agreement with the experimental outcomes reported in the literature [25], showing the appearance of a diagonal and vertical crack patterns. Some non-negligible differences were found in the case of long settlements, where the models predict diagonal cracks from the side of the moving support to the upper edge of the wall, instead of vertical cracks, as expected. Such a discrepancy can be ascribed to the rough simulation of the ground settlement, consisting in a uniform vertical displacement at the moving support.

The results also showed that the value of the vertical reaction which activates the failure mechanism, provided by the homogenized FEA represents an upper bound for the solutions provided by the RBLA. This is not surprising since, according to the homogenization theory, the continuum approach provides reliable results when the size of the block is small enough when compared with the characteristic length of the problem (i.e. the wall's height or width).

\section{ACKNOWLEDGEMENTS}

$\mathrm{T}$ he support of PRIN 2015 Programme by the Ministry of Education, University and Research (MIUR) is acknowledged for funding the research project "Protecting the Cultural Heritage from water-soil interaction related threats - PERICLES" (Prot. No. 2015EAM9S5). The support of Regione Lazio Research Project "SiCura, Sustainable technologies for the seismic protection of the cultural heritage" (Years 2018-2020, Protocol N. 15136) and of ReLuis research program funded by the Italian Department of Civil Protection (Years 2019-2021, Protocol N. 23) are also gratefully acknowledged.

\section{REFERENCES}

[1] Baggio, C., Trovalusci P. (1998) Limit analysis for no-tension and frictional three-dimensional discrete systems, Journal of Structural Mechanics, 26(3), pp. 287-304.

[2] DeJong, M.J. (2016) Settlement effects on masonry structures, Structural Analysis of Historical Constructions: Anamnesis, diagnosis, therapy, controls - Proc. of the 10th Int. Conf. on Structural Analysis of Historical Constructions, SAHC 2016, pp. 449-456.

[3] Cascini, L., Gagliardo, R., Portioli, F. (2018) LiABlock_3D: A Software Tool for Collapse Mechanism Analysis of Historic Masonry Structures, International Journal of Architectural Heritage, Article in Press.

DOI: $10.1080 / 15583058.2018 .1509155$.

[4] Portioli, F., Cascini, L. (2016) Assessment of masonry structures subjected to foundation settlements using rigid block limit analysis, Engineering Structures, 113, pp. 347-361. DOI: 10.1016/j.engstruct.2016.02.002.

[5] Galassi, S., Misseri G., Rovero L., Tempesta, G., (2018) Failure modes prediction of masonry voussoir arches on moving supports, Engineering Structures, 173, pp. 706-717. DOI: 10.1016/j.engstruct.2018.07.015.

[6] Galassi, S., Ruggieri, N., Tempesta, G. (2018) A Novel Numerical Tool for Seismic Vulnerability Analysis of Ruins in Archaeological Sites, International Journal of Architectural Heritage, Article in Press.

DOI: $10.1080 / 15583058.2018 .1492647$.

[7] D’Altri, A.M., De Miranda, S., Castellazzi, G., Sarhosis, V., Hudson, J., Theodossopoulos, D. (2019) Historic Barrel Vaults Undergoing Differential Settlements, International Journal of Architectural Heritage.

DOI: $10.1080 / 15583058.2019 .1596332$.

[8] Angelillo, M., Fortunato, A., Gesualdo, A., Iannuzzo, A., Zuccaro, G. (2018) Rigid block models for masonry structures, International Journal of Masonry Research and Innovation, 3 (4), pp. 349-368.

[9] Di Carlo, F., Coccia, S., Rinaldi, Z. (2018) Collapse load of a masonry arch after actual displacements of the supports, Archive of Applied Mechanics, 88 (9), pp. 1545-1558.

[10] Spada, A. (2019). The effect of vertical ground movement on masonry walls simulated through an elastic-plastic interphase meso-model: a case study, Arch Appl Mech., DOI: https://doi.org/10.1007/s00419-019-01535-y. 
[11] Giardina G., Marini A., Riva P. \& Giuriani E. (2019) Analysis of a scaled stone masonry facade subjected to differential settlements, International Journal of Architectural Heritage. DOI: 10.1080/15583058.2019.1617911

[12] Amorosi, A, Boldini, D, De Felice, G, Malena M. (2012) Tunnelling-induced deformation on a masonry structure: a numerical approach. In: Geotechnical aspects of underground construction in soft ground. Proceedings of the 7th International Symposium on Geotechnical Aspects of Underground Construction in Soft Ground, pp. 353-359.

[13] Amorosi, A, Boldini D, de Felice G, Malena M, Sebastianelli M. (2014) Tunnelling-induced deformation and damage on historical masonry structures. Géotechnique, 64(2), pp. 118-130.

[14] Amorosi A, Boldini D, de Felice G, Lasciarrea WG, Malena M (2016) An integrated approach for geotechnical and structural analysis of the Nynphaeum of Genazzano. Structural Analysis of Historical Constructions: Anamnesis, diagnosis, therapy, controls - Proceedings of the 10th International Conference on Structural Analysis of Historical Constructions SAHC 2016, pp. 503-510.

[15] Lasciarrea WG, Amorosi A, Boldini D, de Felice G, Malena M. (2019) Jointed Masonry Model: A constitutive law for 3D soil-structure interaction analysis. Engineering Structures, 201, 109803.

[16] Torres, B., Bertolesi, E., Calderón, P.A., Moragues, J.J., Adam, J.M. (2019) A full-scale timbre cross vault subjected to vertical cyclical displacements in one of its supports, Engineering Structures, 183, pp. 791-804.

[17] Drougkas, A., Verstrynge, E., Szekér, P., Heirman, G., Bejarano-Urrego, L.-E., Giardina, G., Van Balen, K. (2019) Numerical Modeling of a Church Nave Wall Subjected to Differential Settlements: Soil-Structure Interaction, TimeDependence and Sensitivity Analysis, International Journal of Architectural Heritage, Article in Press.

[18] Tubaldi, E., Macorini, L., Izzuddin, B.A. (2018) Three-dimensional mesoscale modelling of multi-span masonry arch bridges subjected to scour, Engineering Structures, 165, pp. 486-500.

[19] Casalegno, C., Cecchi, A., Reccia, E., Russo, S. (2013) Heterogeneous and continuous models: Comparative analysis of masonry wall subjected to differential settlements, Composites: Mechanics, Computations, Applications, 4(3), pp. 187207.

[20] Zampieri, P., Amoroso, M., Pellegrino, C. (2019) The masonry buttressed arch on spreading support, Structures, 20, pp. 226-236.

[21] Baraldi, D., Cecchi, A., (2018) Discrete and continuous models for static and modal analysis of out of plane loaded masonry, Computers and Structures, 207, pp. 171-186.

[22] Baraldi, D., Boscato, G., De Carvalho Bello, C.B., Cecchi, A., Reccia, E. (2019) Discrete and finite element models for the analysis of unreinforced and partially reinforced masonry arches, Key Engineering Materials, 817, pp. $229-235$.

[23] Malena, M., Portioli, F., Gagliardo, R., Tomaselli, G., Cascini, L., de Felice, G. (2019) Collapse Mechanism Analysis of Historic Masonry Structures Subjected To Lateral Loads: A Comparison Between Continuous And Discrete Models. Computers and Structures, 220, pp. 14-31.

[24] de Felice, G. and Malena, M. (2019) Crack pattern prediction in masonry, Journal of Mechanics of Materials and Structures. DOI: https://doi.org/10.2140/jomms.2019.14.620.

[25] Mastrodicasa S. (1943) Dissesti statici delle strutture edilizie. Diagnosi e Consolidamento, Milan, Italy: Hoepli (in Italian).

[26] de Felice G, Amorosi A, Malena M. (2010) Elasto-plastic analysis of block structures through a homogenization method. Int J Numer Analyt Methods Geomech, 34(3), pp. 221-247.

[27] Sab, K., Cecchi, A., Dallot, J. (2007) Determination of the Overall Yield Strength Domain of Out-of-Plane Loaded Brick Masonry, International Journal for Multiscale Computational Engineering, 5(2), pp. 83-92.

[28] Iannuzzo, A., Angelillo, M., De Chiara, E., De Guglielmo, F., De Serio, F., Ribera, F., Gesualdo, A. (2018) Modelling the cracks produced by settlements in masonry structures, Meccanica, 53(7), pp. 1857-1873.

\section{NomenClature}

$\alpha \quad$ collapse load multiplier

$\boldsymbol{A}$ equilibrium matrix

c vector of contact forces

$f_{D} \quad$ vector of dead loads

$f_{S} \quad$ vector of reaction at the moving support

$\mu \quad$ friction coefficient

$n_{k} \quad$ normal force component at contact point $k$

$t_{1 k} \quad$ shear force component at contact point $k$ along local coordinate axis 1 
$t_{2 k} \quad$ shear force component at contact point $k$ along local coordinate axis 2

$\rho \quad$ unit weight

$\mathrm{t} \quad$ vector collecting the in-plane and the out-of-plane stresses

$\mathrm{N} \quad$ vector collecting the in-plane stresses

$\mathrm{M} \quad$ vector collecting the out-of-plane stresses

$\mathrm{E} \quad$ vector collecting the in-plane strains

$\mathrm{X} \quad$ vector collecting the out-of-plane strains

$\mu_{\mathrm{b}} \quad$ aspect ratio of the blocks

$\mathrm{h}$ thickness of the plate

$\phi \quad$ joint friction

a height of the block

b width of the block 